\title{
AN UNUSUAL CASE OF MULTI-RECURRENT HERPES ZOSTER (HZ): A CASE REPORT
}

\author{
Vanda Bostikova ${ }^{\mathrm{a}}$, Miloslav Salavec ${ }^{\mathrm{b}, *}$, Jan Smetana ${ }^{\mathrm{a}}$, Roman Chlibek ${ }^{\mathrm{a}}$, Pavel Kosina ${ }^{\mathrm{c}}$, \\ Petr Prasil ${ }^{c}$, Stanislav Plisek ${ }^{c}$, Miroslav Splino ${ }^{\mathrm{a}}$, Pavel Bostik ${ }^{\mathrm{a}, \mathrm{c}}$ \\ ${ }^{a}$ Faculty of Military Health Sciences, University of Defence, Hradec Kralove, Czech Republic \\ ${ }^{b}$ Department of Dermatology and 'Department of Infectious Diseases, Charles University Medical School and University \\ Hospital, Hradec Kralove \\ E-mail: salavecm@post.cz
}

Received: July 13, 2011; Accepted with revision: November 15, 2011; Available online: December 20, 2011

Key words: Herpes zoster/Varicella-zoster virus/Wild-type strain/Czech Republic

Aims. We report a case of multi-recurrent herpes zoster in a 53-year-old Caucasian woman treated repeatedly at the Faculty Hospital Hradec Kralove, Czech Republic over the years 2009 - 2011.

Methods. Specific PCR methods targeting single nucleotide polymorphisms (SNPs) in open reading frames (ORF) 38, 54 and 62 were utilized to determine vaccine or wild type varicella-zoster (VZV) strains followed by SNPs analysis using two amplicons in ORF 22 and/or ORF 21/ORF 50. Additional genotyping in ORF 1, 6, 9 and 28 was subsequently performed due to the unusual results.

Results. Three sets of clinical specimens from one patient (from hospital visits 2, 3 and 4) were analyzed and the presence of an unusual wild-type strain of VZV was discovered. The VZV strain isolated from the lesions bears a combination of markers characteristic both for Mosaic 2 (M2) and European 1 (E1) wild-type VZV strains.

Conclusion. This is the first report of atypical wild-type VZV strain circulating currently in Czech Republic.

\section{INTRODUCTION}

Varicella zoster virus (VZV) - a member of the family herpesviridae, is a highly contagious pathogen. Humans represent the only known reservoirs for VZV (ref. ${ }^{1}$ ). The virus is easily spread among people through airborne particles, droplets in exhaled air and fluid from blisters or sores. The virus can be also transmitted indirectly by contact with clothing or other items exposed to open sores.

Primary VZV infection in humans results in chickenpox, which has characteristic clinical manifestations ${ }^{2}$. Secondary VZV infection manifests as herpes zoster (HZ), and is caused by the reactivation of dormant virus in the dorsal root ganglia following primary VZV infection. Zoster can occur at almost any age. It is more frequent in older people with its peak occurring between the age of 60-70, but is not uncommon in immunocompromised and even normal children ${ }^{3,4}$. HZ often presents as painful vesicular rash, which is often unilateral and limited to a single dermatome ${ }^{3,5}$.

The epidemiology of VZV infection varies geographically $^{6}$. Virus displays marked seasonality in temperate climates, and infection is nearly ubiquitous by the age of 20. For no clear reasons, seasonality does not occur in tropical countries, and a larger proportion of people enter adulthood uninfected by VZV (ref. ${ }^{7}$ ). Several studies have demonstrated a distinctive geographic distribution of the major VZV genotypes aligning with cool versus warm climate regions of the globe ${ }^{6}$. It is unclear whether the strain distribution is actually driven by climate or/and other factors, such as immigration patterns ${ }^{7-9}$.
A detailed study of the VZV genome using different genotyping methods leads to better understanding of VZV epidemiology by the means of determining VZV variability $^{6}$. In the context of a vaccination program, information on VZV variation would enable us to differentiate individual strains of VZV, facilitating the identification of the source of VZV outbreaks. Studies utilizing genotyping of VZV based on sequence variations in ORF 21, ORF 22, ORF 50 and other discrimination methods, which utilize the markers in ORF 38, ORF 54 and ORF 62, led to a categorization of VZV. Thus, utilizing these markers, the VZV strains can be categorized as vaccine or wildtype strains and the wild-type strains can be subsequently differentiated into distinct genotypes such as E1 or E2 (European), J (Japanese) or M1 - M4 (mosaic) (ref. ${ }^{7}$ ). The E genotypes are the most prevalent genotype in the United States, Canada, Europe, and eastern Australia. The J genotype is typically found in Japan and Asia.The M genotypes are prevalent mostly in tropical countries, including Panama, Costa Rica, Barbados, Sudan, New Zealand, western part of Australia ${ }^{7-9}$.

\section{CASE REPORT}

A 52 year old Caucasian women was examined (visit 1) on July 2009 at the Department of Dermatology, Faculty Hospital in Hradec Kralove with unilateral papulovesicular exanthema on the extensor site of the left thigh shortly after meniscus surgery. The eruption was preceded by severe burning sensation and pain. The diagnosis of 


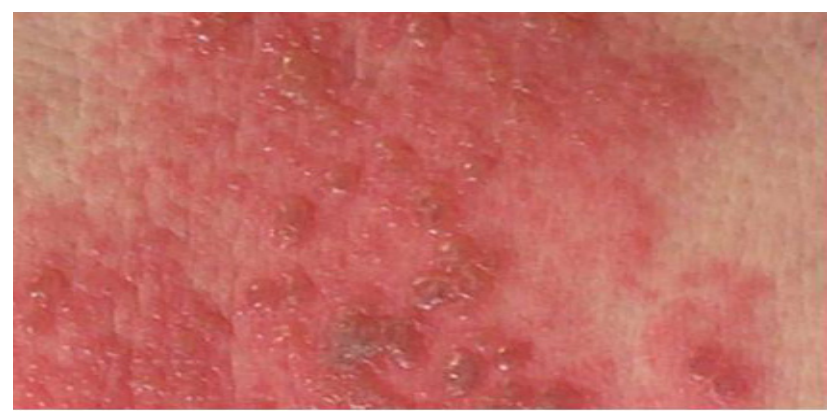

Fig. 1. Herpes zoster - blister formation on the right neck.

herpes zoster was made and treatment by Acyclovir 800 mg every $4 \mathrm{~h}$, five times a day per os was recommended. Topically Endiaron paste (Cloroxinum $1.5 \mathrm{~g} \mathrm{(5 \% ))}$ was applied to dry skin and to prevent secondary bacterial complication. The patient had no history of contact with varicella or herpes zoster at all. Lab tests were performed and the only unusual result showed higher value of $\operatorname{ESR}(16 / 38)$ and also a higher value for absolute number of neutrophils $\left(7.7210^{9} / 1\right)$.

On November 2009, the patient presented again with an acute skin blister eruption localized on the right lateral aspects of the neck region (Fig. 1) (visit 2). She suffered from pain with propagation to her right ear. Vertebrogenic algesic syndrome preceded development of skin lesions. No history of either varicella or herpes zoster contact was recorded and treatment approach identical to the one applied in July 2009 was used. However, this time a sterile swab for sequential analysis of VZV genome was obtained from the lesions. At this time, laboratory results showed an increase in the levels of $\operatorname{IgM}(0.35 \mathrm{~g} / 1)$.

In February 2010, the third attack of herpes zoster was diagnosed (visit 3 ). This time the lesions were localized periorally and on the left part of the chin. The papulovasicular rash was associated with fatigue, subfebrilia $37.6^{\circ} \mathrm{C}$ and with chills, but no history of stress or other disorders preceded the skin lesion formation. Again, no history of varicella or herpes zoster contact was confirmed. Standard therapy by Acyclovoir $5 \times 800 \mathrm{mg}$ orally was initiated with the addition of topical DermoChlorophyl gel to support the epithelization process in erosions following rupture of blister roofs. The swab to obtain material for the sequential analysis of VZV genome was performed again. Again the only unusual laboratory values were a higher ESR (13/36).

In the second half of April 2010, another papulovesicular formation localized in the right supraclavicular region and band-like erythema anterior to the right auricle and right lateral neck region appeared (visit 4). The patient suffered from severe pain with right ear propagation reaching a maximum in the erythematous region of the right musculus sternocleidomastoideus. Paresthetic feelings were localized to the right supraclavicular region. Fatigue, weakness and nausea with chills preceded the rash. Noroviral infections were presented at the workplace during the time of the development of skin lesions. Body temperature (axillary) was $36.6{ }^{\circ} \mathrm{C}$. The therapy by orally administrated Acyclovir 800 mg every $4 \mathrm{~h}$, five times daily, for five days was initiated and followed by prophylactic doses of $2 \times 400 \mathrm{mg}$ daily for about 2 months, then $200 \mathrm{mg}$ daily till the next visit of the patient due to new skin eruptions in September 2010. In addition 1\% Rivanol in shaking mixture and Endiaron paste (Cloroxinum $1.5 \mathrm{~g}(5 \%)$ ) were applied topically. Vitamin B12 1000 i.m. was indicated for supportive care. A swab specimen for VZV genome analysis was obtained from the lesions again. Laboratory tests showed again higher levels of $\operatorname{IgM}(0.37 \mathrm{~g} / 1)$ and higher number of leucocytes (WCC $11.26 \times 10^{9} / 1$ ). Next, the patient presented with a very mild papular exanthema in the right preauricular region in September 2010 (visit 5). A severe headache with intensive pain propagation into pre- and retroauricular regions was reported by the patient one week before skin symptoms developed and were treated by NSAID (Ibuprofenum). The stress reported by the patient lasting more than 3 weeks before skin involvement could have been regarded as the triggering factor. No history of chill or frozen sensation was associated with this exanthema. Body temperature was $36.6^{\circ} \mathrm{C}$. The standard management

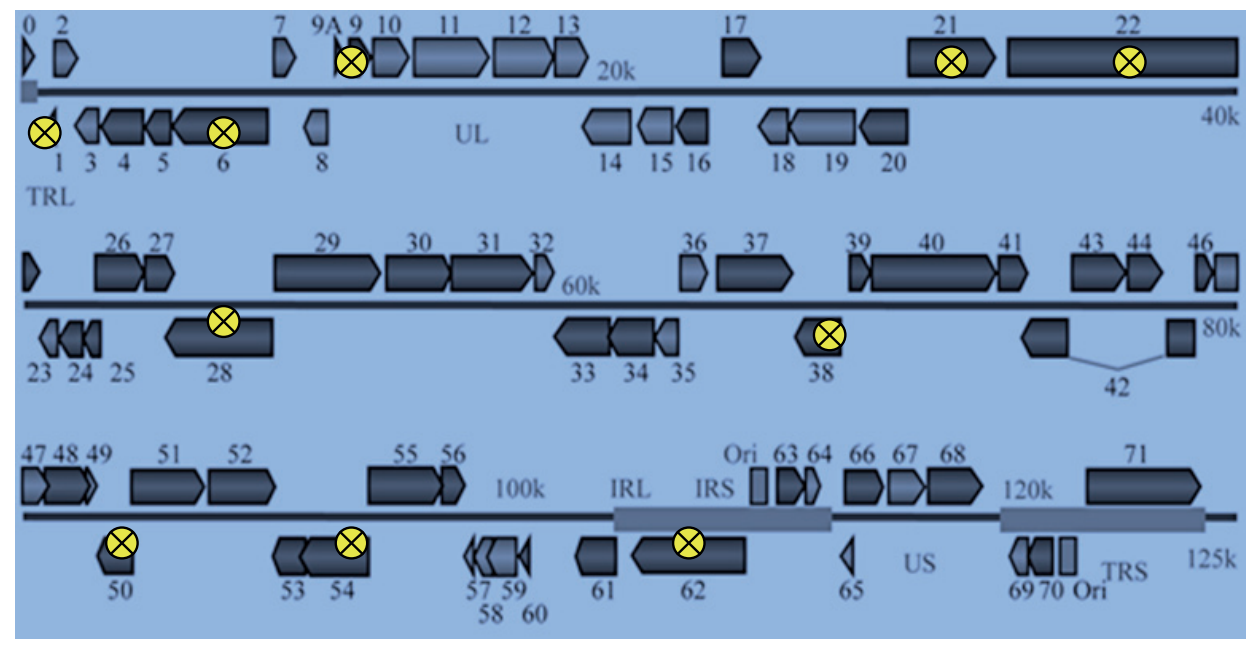

Fig. 2. Genome of varicella-zoster virus $(125,000 \mathrm{bp})$. Yellow marks show the ORFs analyzed by genotyping. 
for $\mathrm{HZ}$ with Acyclovir 5x800 mg was started again and subsequent prophylactic treatment $800 \mathrm{mg}(2 \times 400 \mathrm{mg})$ of the same drug daily for one month was recommended. Biochemistry was analyzed twelve days before the first skin symptoms developed with normal results and total reactive protein was in the normal range $(2.2 \mathrm{mg} / 1)$. Anti VZV IgM antibodies were found negative, whereas IgG were positive - 45.1. The value of leucocytes was higher $\left(9.97 \times 10^{9} / 1\right)$. Otoscopy examination revealed no involvement of the ear structures.

\section{MATERIAL AND METHODS}

Material from clinical specimens (visit 2, 3 and 4) of vesicular fluid was collected onto cotton swabs and air dried. DNA samples from these specimens were isolated using MagNA Pure LC machine (Roche Molecular Biochemicals, Madison, WI). Further analysis was perfomed as described below and all the ORF sequences analyzed are shown in (Fig. 2). The LightCycler real-time PCR hybridization probe-based assays to detect VZV (PCR) and genotype (melt curve analysis) VZV strains based on the presence or absence of a BglI, PstI restriction sites within ORF 54, 38 and 62, respectively were used. BgII and PstI was used for classification of global VZV genomic variance; SmaI and MspI markers distinguish wild type VZV strains from Oka vaccine strains ${ }^{8,10,11}$ PCR amplifications of the ORF21 - 502 bp target region,

Table 1. Laboratory results of immunological tests.

\begin{tabular}{|l|c|c|}
\hline Test type / Visit number & Visit 2 & Visit 4 \\
\hline Leukocytes & $7.8 .10^{9} / 1$ & \\
\hline CD4+ T lympho relat. No. & $62.5 \%$ & \\
\hline CD8+ T lympho relat. No. & $14.9 \%$ & \\
\hline Lymphocytes absol. No. & $2.5 \mathrm{E} 9 / 1$ & \\
\hline Lymphocytes relat. No. & $32.3 \%$ & \\
\hline NK cells relat. No. & $10.6 \%$ & \\
\hline CD19+ B lympho relat. No. & $12.7 \%$ & \\
\hline CD3+ T lympho relat. No. & $74.1 \%$ & \\
\hline CD19+ B lympho absol. No. & $0.32 \mathrm{E} 9 / 1$ & \\
\hline CD3+ T lympho absol. No. & $1.85 \mathrm{E} 9 / 1$ & \\
\hline CD4+ T lympho absol. No. & $1.56 \mathrm{E} 9 / 1$ & \\
\hline CD8+ T lympho absol. No. & $0.37 \mathrm{E} 9 / 1$ & \\
\hline NK cells absol. No. & $0.27 \mathrm{E} 9 / 1$ & \\
\hline IgA & $1.23 \mathrm{~g} / 1$ & $1.41 \mathrm{~g} / 1$ \\
\hline IgG & $11.8 \mathrm{~g} / 1$ & $12.3 \mathrm{~g} / 1$ \\
\hline IgM & & $0.37 \mathrm{~g} / 1$ \\
& $0.35 \mathrm{~g} / 1 \mathrm{H}$ & $(\mathrm{Range}$ \\
\hline Range & & $0.4-3.0)$ \\
\hline IgG2 & $7.4 \mathrm{~g} / 1$ & \\
\hline IgG3 & $3.93 \mathrm{~g} / 1$ & \\
\hline IgG4 & $0.55 \mathrm{~g} / 1$ & \\
\hline
\end{tabular}

$\mathrm{H}$ - High (increased levels)

Absol. No. - absolute numbers
ORF22 - 447 bp target region, ORF50 - 514 bp target region were performed with a GeneAmp PCR System 9700 (Applied Biosystems, Carlsbad, CA) using $5 \mu$ of DNA extracted from skin lesions of the patient. PCR products were separated on $4 \%$ precast gradient polyacrylamide gels prestained with ethidium bromide (Invitrogen) and visualized under UV irradiation alongside a 100-bp ladder (Invitrogen $)^{7-9,11,12}$. Similar methods were used for multi-locus DNA sequence analysis at ORF 1,6, 9 and 28. All genomic loci refer to the published sequence for the Dumas strain (Genbank accession \#9625875). The sequences of primers and probes were described and published previously ${ }^{6-9,11,12}$. Automated DNA sequencing was performed using the Genomelab GeXP (Beckman Coulter, Fullerton, CA) according to the manufacturer's instructions. Primary DNA sequence assembly and analysis were performed with BioEdit Sequence Alignment Editor (www.mbio.ncsu.edu/BioEdit/bioedit.html programs), and the sequences was compared with that of VZV strain Dumas (GenBank accession \#9625875) in order to locate SNPs.

\section{RESULTS}

Each clinical specimen obtained from patient's visits 2, 3 and 4 was at first confirmed to be PCR positive for the wild-type VZV. None of the VZV isolates from this patient carried any of the vaccine-associated markers. Further genotyping effort based on previously published 447-bp amplicon in ORF 22R1( ref. $^{8}$ ) plus variation in targeted SNPs in either ORF 21 or ORF 50 (ref. ${ }^{8,9}$ ) categorized VZV wild-type strains to different wild-type genotypes of VZV (ref. ${ }^{9}$ ). Swabs were positive for M2 strain on the basis of genotyping data for ORF 22 and for E1 strain as the result of genotyping ORF 21 and ORF 50. We performed additional genotyping for ORF 1, 6, 9 and 28 for each clinical specimen. The results showed the sequences in ORF 1, ORF 6 and ORF 28 to be characteristic for M genotype, more specifically M2 (on the basis of ORF 28) and sequences in ORF 9 as E genotype ${ }^{12}$. All swabs from each individual skin lesions contained this identical pattern of a variant of wild-type VZV strain. Mozaic M strains are typically found in tropical countries and European E strains are typical for VZV isolates in Europe $e^{2,6,7,9}$. This is the first finding of this kind of strain in the Czech Republic. However, only a small number of clinical samples have been analyzed to date in this country $y^{2,7,9}$ and therefore there may be others circulating in the population.

Due to the atypical course of recurrent herpes zoster we analyzed in detail other anamnestic data in this patient. The entire set of laboratory data from immunological, haematological and biochemistry tests were analyzed as well and are displayed in (Table 1-3). Interestingly, a broad laboratory screening did not show any defect of the immune system. As mentioned above, the patient was a 53 year old Caucasian woman treated for atopic dermatitis since 1994. Clinically she was diagnosed as a late form of atopic disorder with symptoms involving 
Table 2. Laboratory results of hematological parameters.

\begin{tabular}{|l|c|c|c|c|c|}
\hline \multicolumn{1}{|c|}{ Test type/ Visit number } & Visit 1 & Visit 2 & Visit 3 & Visit 4 & Visit 5 \\
\hline ESR 1h/2h & $16 / 38 \mathrm{H}$ & & $13 / 36 \mathrm{H}$ & & \\
\hline Leucocytes (WCC) & $11.8110^{9} / 1$ & $7.7510^{9} / 1$ & $9.1410^{9} / 1$ & $11.2610^{9} / 1 \mathrm{H}$ & $9.9710^{9} / 1 \mathrm{H}$ \\
\hline Erythrocytes (RBCC) & $4.6210^{12} / 1$ & $4.4710^{12} / 1$ & $4.8810^{12} / 1$ & $4.8310^{12} / 1$ & $4.6910^{12} / 1$ \\
\hline Haemoglobin & $137 \mathrm{~g} / 1$ & $131 \mathrm{~g} / 1$ & $145 \mathrm{~g} / 1$ & $142 \mathrm{~g} / 1$ & $138 \mathrm{~g} / 1$ \\
\hline Haematocrit (PCV) & 0.400 & 0.388 & 0.414 & 0.412 & 0.401 \\
\hline Thrombocytes (PC) & $24110^{9} / 1$ & $25110^{9} / 1$ & $24810^{9} / 1$ & $25210^{9} / 1$ & $25810^{9} / 1$ \\
\hline Neutrophils absol. No. & $7.7210^{9} / 1 \mathrm{H}$ & $4.3610^{9} / 1$ & & $7.7210^{9} / 1 \mathrm{H}$ & \\
\hline Basophils abol. No. & $0.0810^{9} / 1$ & $0.0510^{9} / 1$ & & $0.0610^{9} / 1$ & \\
\hline Monocytes absol. No. & $0.9510^{9} / 1$ & $0.6710^{9} / 1$ & & $0.8210^{9} / 1$ & \\
\hline Eosinophils absol. No. & $0.1810^{9} / 1$ & $0.1710^{9} / 1$ & & $0.2210^{9} / 1$ & \\
\hline Lymphocytes absol. No. & $2.8710^{9} / 1$ & $2.5010^{9} / 1$ & & $2.4410^{9} / 1$ & \\
\hline Neutrophils & 0.654 & 0.563 & & 0.685 & \\
\hline Eosinophils & 0.016 & 0.022 & & 0.020 & \\
\hline Basophils & 0.007 & 0.006 & & 0.005 & \\
\hline Lymphocytes & 0.243 & 0.323 & & 0.217 & \\
\hline Monocytes & 0.080 & 0.086 & & 0.073 & \\
\hline
\end{tabular}

PC - Platelet count

PCV - Packet cell volume
RBCC - Red blood cell count WCC - White cell count
$\mathrm{H}$ - High (increased levels)

Absol. No. - absolute numbers

Table 3. Biochemistry analysis.

\begin{tabular}{|c|c|c|c|c|}
\hline Test type/Visit number & Visit 1 & Visit 3 & Visit 4 & Visit 5 \\
\hline Glucose S mmol/1 & & 6.1 & & \\
\hline Natrium S mmol/1 & 141 & 141 & 142 & \\
\hline Kalium S mmol/1 & 4.1 & 4.3 & 4.3 & \\
\hline Chloride S mmol/1 & 106 & 104 & 106 & \\
\hline Urea S mmol/1 & 6 & 4.8 & 4.4 & \\
\hline Creatinine S umol/1 & 81 & 72 & 73 & \\
\hline Uric acid $\mathrm{S}$ umol/1 & 316 & 262 & 327 & \\
\hline Bilirubin S umol/1 & 7 & 4 & 8 & \\
\hline ALT S (SGPT) ukat/1 & 0.46 & 0.36 & 0.48 & \\
\hline AST S (SGOT) ukat/1 & 0.36 & 0.37 & 0.36 & \\
\hline GMT S (SGGT) ukat/1 & & 0.43 & 0.33 & \\
\hline ALP S ukat/1 & & 1.44 & 1.43 & \\
\hline CHOL S mmol/1 & & 3.74 & & \\
\hline PROT S g/1 & & 72.9 & & \\
\hline CRP S mg/1 & 3.2 & 3.1 & & 2.2 \\
\hline $\mathrm{SG} \mathrm{U} \mathrm{kg/ \textrm {m } ^ { 3 }}$ & 1016 & 1009 & & \\
\hline $\mathrm{pH} \mathrm{U}$ & 5.5 & 5 & & \\
\hline PROT U arb. units & 0 & 0 & & \\
\hline GLUC U arb. units & 0 & 0 & & \\
\hline KETO U arb. units & 0 & 0 & & \\
\hline UBG U arb. units & 0 & 0 & & \\
\hline BILI U arb. units & 0 & 0 & & \\
\hline BLOOD U arb. units & 1 & 0 & & \\
\hline ERY U & $1610^{6} / 1$ & $210^{6} / 1$ & & \\
\hline LEUC U & $710^{6} / 1$ & $210^{6} / 1$ & & \\
\hline \multicolumn{3}{|l|}{ ALP Alkaline Phosphatase } & \multicolumn{2}{|c|}{ GLUC U - Glucose urine } \\
\hline \multirow{2}{*}{$\begin{array}{l}\text { ALT Alanine Transaminase (SGPT-serum } \\
\text { glutamic pyruvic transaminase) }\end{array}$} & \multicolumn{2}{|c|}{ PROT U - Protein urine } & \multicolumn{2}{|c|}{ KETO U - Ketones urine } \\
\hline & \multicolumn{2}{|c|}{ CRP - Total reactive protein } & \multicolumn{2}{|c|}{ LEUC U - Leucocytes urine } \\
\hline \multirow{2}{*}{$\begin{array}{l}\text { AST Aspartate Transaminase (SGOT-Serum } \\
\text { glutamic oxaloacetic transaminase) }\end{array}$} & \multicolumn{2}{|c|}{$\mathrm{S}-$ Serum } & \multicolumn{2}{|c|}{ SG U - Urine specific gravity } \\
\hline & \multicolumn{2}{|c|}{ BILI U - Bilirubin urine } & \multicolumn{2}{|c|}{ UBG U - Urobilonogen urine } \\
\hline $\begin{array}{l}\text { CHOL S - Cholesterol serum } \\
\text { GMT Gamma Glutamyl Transferase (SGGT) }\end{array}$ & \multirow{2}{*}{\multicolumn{2}{|c|}{$\begin{array}{l}\text { BLOOD U - Blood urine (Haematuria) } \\
\text { ERY U - Erythrocytes urine }\end{array}$}} & \multirow{2}{*}{\multicolumn{2}{|c|}{ U - Urine }} \\
\hline GMT Gamma Glutamyl Transferase (SGGT & & & & \\
\hline
\end{tabular}


flexural aspects of the extremities, neck and face regions. Corticosteroids as well as immunomodulatory agents (calcineurin inhibitor tacrolimus, Protopic ${ }^{\circledR} 0.1 \%$ ointment) were administrated topically. Antihistamines were used perorally for systemic treatment (desloratadinum $5 \mathrm{mg}$ / tbl., Aerius ${ }^{\circledR}$ tbl.). The patient had been treated for allergic rhinoconjunctivitis and moderate bronchial asthma for several years by a combination of Alvesco ${ }^{\circledR} 160$ inhaler (ciclesonidum, inhalatory corticosteroid), Avamys nasal spray $^{\circledR} 120 x 27.5 \mathrm{RG}$ (fluticasoni fuoras $27.5 \mu \mathrm{g} / 1$ dose) and Opatanol ${ }^{\circledR}$ gtts $3 \times 5 \mathrm{ml}$ (olopatadini hydrochloridum $1 \mathrm{mg} / 1 \mathrm{ml}$ ). Allergological tests confirmed a hypersensitivity to grass and birch pollen, in addition to a sensitivity to mites and dog hair. Several other disorders were confirmed in her personal case history: arterial hypertension, hyperlipidemia, ischemic heart disease (variant angina pectoris), liver steatosis according to ultrasound examination, cervicobrachial syndrome, cholecystolithiasis, colon polyposis (hyperplastic polypuses histologically). In 1978 cervix conization due to precanceromatous lesion was performed. Other pathologic conditions in the past included left humeroscapular arthritis, appendectomy, degenerative involvement of intervertebral discs L1-S1 (lumbal vertebrogenic algesic syndrome diagnosed about 2 weeks before one clinical manifestation of $\mathrm{HZ}$ ), left gonarthrosis of I.- II. grade and finally bilateral cataract surgery in 1998.

\section{CONCLUSION}

The incidence of $\mathrm{HZ}$ is sporadic in the Czech Republic. The average incidence was 6,300 cases/year for the last decade. The incidence is different in males and in females. Thus, a 1.4 fold higher incidence was recorded for women than men on a long-term basis. While zoster can occur at any age, the risk of herpes zoster development is distinctively higher in elderly patients. The peak incidence was confirmed in patients over seventy years of age to be $155 / 100,000$ in 2008 , whereas the average incidence at the same time was $61.3 / 100,000$. Increased zoster cases numbers were noted in the age subgroup of 45-49 years. Patients over fifty years of age reached higher sickness rates when the data for 2008 were analyzed. The peak incidence in children (age group 10-14) and adolescents in 2008 reached 49.4/100,000. Analysis of different clinical forms of herpes zoster reported to the Epidat system (www.szu.cz) showed that the uncomplicated herpes zoster was the most frequent reported form. The most frequent complication of herpes zoster included neurological involvement (meningitis, encephalitis and other CNS complications - 30, 21 and 20 cases respectively), ophthalmic involvement (94 cases) and generalized herpes zoster (zoster generalisatus, 13 reported cases) (ref. ${ }^{3}$ ).

Four to six patients with herpes zoster per month are approximately diagnosed in our out -patient dermatological department at Faculty Hospital in Hradec Kralove, Czech Republic. In 2008, HZ was diagnostically confirmed in a total number of 67 patients and in 4 patients hospital admission was necessary. In 2009, diagnosis of $\mathrm{HZ}$ was made in 49 patients, but all of them were treated as out-patients. Until August 2010, a total number of 37 patients presented with $\mathrm{HZ}$ and one patient needed hospital admission.

This report describes for the first time the presence of an unusual M2/E1 strain in Czech Republic. Further molecular analysis focused on the monitoring of VZV vaccination program in this country is needed.

\section{ACKNOWLEDGEMENTS}

This work was supported by grant P304/10/1161 from the Grant Agency of Czech Republic.

\section{REFERENCES}

1. Arvin AM. Varicella-zoster virus: overview and clinical manifestations. Semin Dermatol 1996;15:4-7.

2. Bostikova V, Salavec M, Splino M, Chlibek R, Smetana J, Vackova M, Hanovcova I, Bostik P. The role of sequence analysis of wildtype varicella-zoster virus in epidemiological and evolutionary characterization of VZV:focus on epidemiologic situation in Czech Republic. Vakcinologie 2010;2(4):55-9 (in Czech).

3. Smetana J, Salavec M, Bostikova V, Chlibek R, Bostik P, Hanovcova I, Vackova M, Matulkova P, Splino M. Herpes zoster in Czech Republic - epidemiology and clinical symtoms. EMI 2010;3:138-46 (in Czech).

4. Sutradhar SC, Wang WW, Schlienger K, Stek JE,Xu J,., Chan IS, Silber JL. Comparison of the levels of immunogenicity and safety of Zostavax in adults 50 to 59 years old and in adults 60 years old or older. Clin Vaccine Immunol 2009;16(5):646-52.

5. Sampathkumar P, Drage LA, Martin DP. Herpes zoster (shingles) and postherpetic neuralgia. Mayo Clin Proc 2009;84(3):274-80.

6. Larussa PS, Gershon AA. Biologic and geographic differences between vaccine and clinical varicella-zoster virus isolates. Arch Virol Suppl 2001;41-8.

7. Loparev VN, Gonzalez M, Deleon-Carnes M, Tipples G, Fickenscher E., Torfason E, Schmid DS. Global identification of three major genotypes of varicella-zoster virus: longitudinal clustering and strategies for genotyping. J Virol 2004;78;8349-58.

8. Loparev VN, Rubtcova EN, Bostik V, Govil D, Birch CJ, Druce JD, Schmid DS, Croxson MC. Identification of five major and two minor genotypes of varicella-zoster virus strains: a practical twoamplicon approach used to genotype clinical isolates in Australia and New Zealand. J Virol 2007;81(23):12758-65.

9. Loparev VN, Rubtcova EN, Bostik V, Tzaneva V, Sauerbrei A, Robo A, Sattler-Dorbacher E, Hanovcova I, Stepanova V, Eremin V, Koskiniemi M, Vankova OE, Schmid SD.Distribution of varicellazoster virus (VZV) wild type genotypes in northern and southern Europe: evidence for high conservation of circulating genotypes. Virology 2009;383(2):216-25.

10. LaRussa P, Lungu O, Hardy I, Gershon A, Steinberg SP, Silverstein $\mathrm{S}$. Restriction fragment length polymorphism of polymerase chain reaction products from vaccine and wild-type varicella-zoster virus isolates. J Virol 1992;66:1016-20.

11. Loparev VN, McCaustland BP, Holloway PR, Takayama M, Schmid DS. Rapid genotyping of varicella-zoster virus vaccine and wildtype strains with fluorophore-labeled hybridization probes. J Clin Microbiol 2000;38:4315-19.

12. Loparev VN, Rubtcova E, Seward J, Schmid DS, Levin M. DNA Sequence Variability in Isolates Recovered from Patients with Postvaccination Rash or Herpes Zoster Caused by Oka Varicella Vaccine. J Infect Dis 2007;195:802-10. 
